\title{
The Penelope Gray-Allan Memorial CJEM Writing Award
}

\section{The other side of the curtain}

\author{
Leo R. Carroll, BSc, MD*
}

"Residency is hard, and it's supposed to be hard."

Words that echo in my mind from my first days as a resident - a newly minted doctor embarking on a 5-year journey to transform me into an emergency physician. A journey filled with sleepless nights, crowded waiting rooms, and an endless barrage of questions; I knew these were coming, and I knew it would be hard. But it's not supposed to be this hard.

I held my lifeless newborn son in my arms today.

We knew it was coming, but, despite a slow trickle of bad news, nothing could prepare us enough. Nothing could prepare us for the moment that we held our son, eyes closed, limp limbs, and with a striking resemblance to our other two children.

After two uneventful pregnancies, we expected a third - why wouldn't we? Much to our shock, and initial dismay, the first ultrasound showed two heartbeats: twins. Although unexpected, we opened our hearts and began to contemplate an unimagined future. We adjusted plans for my training, our home life, and careers. We were all in. This was our new reality for a few short weeks.

I had just drifted off to sleep when my wife came back to our room. Her voice shaking...bleeding and cramping. A story heard far too often, but this time was different. This time it's my wife. This time it's my babies.

Shaking off my sleep, I struggle to find that perfect balance of identities: comforting husband, concerned parent, and emergency physician. I gently pepper her with questions, form an impression, and we come up with a plan. The bleeding had stopped, so we would wait until morning. We lay there. Trying to sleep. Contemplating a shift in our new reality. I offer reassurance during what would be the first of many sleepless nights over the next 5 months.

We lost one twin after a placental abruption.

On a nightshift, not long after, I reach for the next chart. A quick glance confirms my fears, as it's a young

woman with a first trimester bleed. I want a different chart, but there's no avoiding it.

She tells me her story with a shaking voice...bleeding and cramping. I grab the ultrasound and locate the baby's heartbeat. I offer her, and myself, reassurance that the baby is still there and the heart is pounding away. A sense of relief washes over her, melting away her anxiety, but I tell her that I can't fully reassure her. I organize a follow-up, another ultrasound, and I advise her to be cautiously optimistic. She smiles and thanks me, but she will never know that I sat in that seat with my wife not long ago. The harbinger of what would be the worst months of our lives.

My wife's follow-up ultrasound raised concern about the remaining twin's heart. Something was wrong: a severe structural cardiac defect. A high-risk surgery in the first weeks of life was the only option, and it was complicated. Multiple valve replacements and revisions, rebuilding the aorta, and long-term Intensive Care Unit admission lay ahead, but we were all in.

Another nightshift: my patient, a woman with multiple valve replacements, on warfarin, coming in septic with hemoptysis, had been dealt a bad hand. Pulmonary hemorrhage? Bronchiectasis? Infective endocarditis? I treat her broadly, and I broach the same questions as the last time she came here - goals of care? My 4 AM brain plays tricks on me. I see myself standing there, on the other side of the curtain, next to my son, and we're contemplating the same questions. How far do we go? Are we still all in?

The amniocentesis results come back showing a genetic disorder - not terminal, but not good. I've seen these kids before - too many times already. Nonverbal, uncooperative, sometimes aggressive, care workers at their side who "sort of know them." They're complicated. After nine specialists, countless appointments, and months of trepidation, the numbers began to stack against us. Whether I

From the *Department of Emergency Medicine, University of Ottawa, Ottawa, ON.

Correspondence to: Dr. Leo Carroll, Department of Emergency Medicine, University of Ottawa, The Ottawa Hospital - Civic Campus, 1053 Carling Ave., E-Main, Room EM-206, Ottawa, ON K1Y 4E9, Canada; Email: Icarr064@uottawa.ca

(C) Canadian Association of Emergency Physicians

CJEM 2018;20(3):461-462

DOI 10.1017/cem.2018.385 
want to or not, I stand there - one foot firmly planted on the inside of the curtain, and the other foot outside. Like dueling personalities, they battle - one informing the other and my internal struggle raging.

We decide to palliate after birth.

We're taught how to break bad news, but, in the emergency department, the clinical picture is evolving and we don't always know how things will end up. I'll never forget the look on my kids' faces when we told them we had lost one twin. When we told them there was a problem with the other twin's heart, and it couldn't be fixed. When we told them their brother's name... and that, although Lachlan wouldn't live long, we would have some time with him. I'll also never forget when I told them Lachlan had died unexpectedly on the morning of my wife's induction, so we wouldn't have any of that promised time. Like a slow drip, this infusion of agony has been running into my veins, but as I dress Lachlan's body in the onesie his brother chose for him, it is wide-open.
These bags are heavy - heavier than when I brought them into the hospital. My mind flashes to the patients I've seen arriving with luggage. In the past, I cynically pondered why they would pack so much, but now it doesn't seem so unreasonable. We expected to have a few days with Lachlan, and we packed for it. But, how do you pack when you're planning to say goodbye? I'm sure these bags will get lighter, but not today. Not the day we leave a piece of ourselves behind.

I've done this walk before - the journey from the far corner of the hospital out to my car. I've done this walk many times before, but never like this. In my short time here, I've watched husbands, wives, and children do this walk - and, although we've walked the same path, I've never truly walked in their footsteps...until now.

Acknowledgements: To my brilliant and resilient wife Emily Cordonier, your strength continues to inspire me. To my children Lucas and Rowan, stay curious and keep asking questions. To my son Lachlan, you will always be in our hearts. 